\title{
TOP COYS (AUTOMATED PLANT CONTROLLING SYSTEMS): SOLUSI PENGENDALIAN LINGKUNGAN PADA BUDIDAYA BUNGA KRISAN DI ASOSIASI TANI “ASTHA BUNDA" KALIURANG
}

\author{
Haris Erdyanto', ‘Arif Lutfi Fuadi², Galih Jefry Sagita ${ }^{3}$, Masruroh $^{4}$, Herlambang Sigit Pramono \\ 1,2, 3, 4,5 Pendidikan Teknik Elektro, Fakultas Teknik, UNY \\ e-mail : hariserdyanto99@gmail.com
}

\begin{abstract}
The purpose of applying this tool on this research is to find out the design of TOP COYS (Automated Plant Controlling Systems), to know how TOP COYS works and to know the productivity of chrysanthemum farmers after using TOP COYS technology. This research was conducted at association of chrysanthemum farmers of ASTHA BUNDA located at Kaliurang street Km. 21 Pakembinangun village, Pakem Sub-district, Sleman. Implementation of the program is conducted for 3 months from March to May 2017. The method in this research is to make the initial design that is adjusted to the land, refining the tool, performing the improved tool test, implementing the tool and monitoring and evaluating the performance of the tool to increase productivity chrysanthemum flower. The expected output from this research is to build TOP COYS in accordance with the partner land condition as the main product of this research, TOP COYS able to increase the productivity and quality of chrysanthemum plants,
\end{abstract}

Keywords: TOP COYS, Chrysanthemum Flowers, Productivity

\begin{abstract}
ABSTRAK
Tujuan penerapan alat ini antara lain untuk mengetahui desain TOP COYS (Automated Plant Controlling Systems), mengetahui cara kerja TOP COYS dan mengetahui produktivitas petani krisan setelah menggunakan teknologi TOP COYS. Penelitian ini dilaksanakan di asosiasi petani bunga krisan ASTHA BUNDA yang terletak di Jalan Kaliurang Km. 21 Desa Pakembinangun, Kecamatan Pakem, Sleman. Pelaksanaan program dilakukan selama 5 bulan yaitu bulan Maret sampai Mei 2017. Metode dalam program ini yaitu melakukan perancangan awal yang disesuaikan dengan lahan, menyempurnakan alat, melakukan uji alat yang telah disempurnakan, melakukan implementasi alat dan melakukan monitoring serta evaluasi terhadap kinerja alat untuk meningkatkan produktifitas bunga krisan. Luaran yang diharapkan dari penelitian ini yaitu terciptanya TOP COYS sesuai dengan kondisi lahan mitra sebagai produk utama dari penelitian ini, TOP COYS mampu meningkatkan produktifitas dan kualitas tanaman bunga krisan,
\end{abstract}

Kata Kunci : TOP COYS, Bunga Krisan, Produktifitas

\section{PENDAHULUAN}

Tanaman krisan termasuk tanaman perdu yang tumbuh semusim, dengan batang tegak kokoh, bulat, berwarna hijau, sisi bawah berwarna hijau muda dengan rambut putih yang rapat, mahkota tabung berwarna kuning dengan mahkota bunga tepi mempunyai warna bervariasi seperti putih, merah muda, kuning dan merah. Tanaman Krisan dapat tumbuh dengan baik di dataran tinggi dengan ketinggian >800 mdpl dan $\mathrm{pH}$ tanah optimal 5,6-6,5 (Crater, 1980). Tanaman krisan membutuhkan suhu hangat untuk pertumbuhannya. suhu terbaik untuk perumbuhan krisan yaitu $+24^{\circ} \mathrm{C}$ pada siang hari dan $+18^{\circ} \mathrm{C}$ pada malam hari. Selain itu selama pertumuhan dan perkembangan tanaman krisan membutuhkan air yang memadai (Fides, 1990). Menurut Kofranek (1980), untuk menumbuhkan stek tanaman krisan perlu suhu udara $+15,5^{\circ} \mathrm{C}$ dengan suhu media $+21^{\circ} \mathrm{C}$. Pembibitan terhadap tanaman krisan membutuhkan kelembaban yang tinggi yaitu 90-95\% untuk pembentukan awal akar bibit dari stek, sedangkan Relative Humidity ( $\mathrm{RH}$ ) untuk tanaman muda hingga dewasa sekitar 70-80\% 
dan diimbangi dengan sirkulasi udara yang memadai (Ibujempol.com)

Bunga Krisan termasuk jenis tanaman hari pendek yang perkembangan dan inisi bunganya dipengaruhi oleh lama penyinaran. Tanaman krisan membutuhkan penyinaran lebih dari 13 jam setiap harinya untuk dapat tumbuh secara vegetatif. Di Indonesia kebutuhan penyinaran tanaman krisan tersebut tidak dapat terpenuhi karena Indonesia berada diwilayah tropis dimana lama penyinarannya rata-rata hanya 12 jam sehari. Budidaya tanaman krisan yang dilakukan di Indonesia perlu mendapatkan pencahayaan tambahan dari lampu listrik (Fides, 1990).

Cuaca yang tidak menentu seperti saat ini mengakibatkan banyak petani bunga krisan yang mengalami kesulitan untuk melakukan pengendalian lahan kebunnya agar cocok dengan lingkungan untuk penanaman bunga krisan. Akibatnya keuntungan yang didapatkan petani menurun drastis karena kualitas bunga krisan yang dihasilkan juga menurun. Pencahayaan tambahan juga menjadi masalah tersendiri karena petani bunga krisan hanya mengandalkan lampu TL berdaya tinggi untuk mendapatkan lux yang tepat bagi pertumbuhan bunga krisan, akibatnya biaya pengeluaran untuk listrik yang dibutuhkan pun bertambah.

Berdasarkan permasalahan yang ada tersebut kami memberikan solusi kontrol dan manipulasi pengendalian lingkungan untuk membantu petani bunga krisan ASTHA BUNDA menggunakan sensor dan alat-alat otomatis yang dapat bekerja sepanjang hari baik siang maupun malam.

Tujuan pelaksanaan program ini yaitu mampu memahami prinsip kerja, penerapan, keunggulan dan kebermanfaatan TOP COYS untuk meningkatkan produktivitas tanaman.

\section{BAHAN DAN METODE}

Waktu pelaksanaan penelitian ini dilaksanakan pada bulan Maret sampai Mei 2017. Pelaksanaan program dilaksanakan di tempat mitra yaitu Asosiasi Tanaman Hias
Bunga dan Daun (ASTHA BUNDA) yang beralamatkan di Jalan Kaliurang Km 21, Desa Pakembinangun, Kecamatan, Pakem, Sleman, Yogyakarta. Pembuatan dan pengujian dilakukan di bengkel pribadi yang terletak di Jalan Kalimantan A29, Purwosari, Sinduadi, Mlati, Sleman, Yogyakarta.

Tahap persiapan umum ini meliputi kunjungan mitra ke asosiasi tani ASTHA BUNDA Kaliurang, studi pustaka, konsultasi dengan dosen pembimbing, perancangan TOP COYS, dan menganalisis kebutuhan alat dan bahan. Kunjungan mitra ke ASTHA BUNDA bertujuan untuk meninjau ulang penerapan teknologi yang telah dibuat serta menjalin komunikasi yang baik dengan mitra. Studi pustaka dilakukan untuk mencari solusi terbaik bagi permasalahan yang ditemui di asosiasi tani ASTHA BUNDA. Kemudian dilakukan konsultasi dengan dosen pembimbing untuk mendapatkan saran yang terbaik dalam membuat TOP COYS sebagai solusi dari permasalahan mitra. Perancangan desain TOP COYS dilakukan dengan analisis yang matang agar nantinya produk yang dibuat sesuai dengan target luaran dan kondisi lapangan. Setelah desain didapatkan, langkah selanjutnya adalah menganalisis kebutuhan alat dan bahan yang sesuai. Kemudian dilakukan pembelian alat dan bahan untuk proses pembuatan dan implementasi TOP COYS.

\section{Pengembangan Produk Awal TOP COYS}

Pembuatan produk TOP COYS meliputi pemrograman pada Arduino Mega 2560 yang merupakan pusat kontroler alat. Pemrograman Arduino Mega 2560 ini disesuaikan logikanya dengan kajian pustaka dan kebutuhan di lapangan.

Arduino Mega 2560 adalah papan pengembangan mikrokontroller yang berbasis Arduino dengan menggunakan chip ATmega2560. Board ini memiliki pin $\mathrm{I} / \mathrm{O}$ sejumlah 54 buah digital I/O pin (15 pin diantaranya adalah PWM), 16 pin untuk analog input, 4 pin untuk UART (serial port hardware). 
Arduino Mega 2560 dilengkapi dengan sebuah oscillator $16 \mathrm{Mhz}$, sebuah port USB, power jack DC, ICSP header, dan tombol reset. Arduino Mega 2560 telah memiliki perangkat yang lengkap untuk kebutuhan dalam sebuah pemrograman mikrokontroller.

Arduino adalah platform prototipe elekronik open-source, yang berdasarkan rangkat keras dan lunak yang fleksibel dan mudah digunakan. Arduino hardware berbentuk rangkaian elektronik dengan ukuran yang kecil dan berfungsi sebagai pengendali. Alat ini dapat dihubungkan dengan sensor yang akan memberikan informasi keadaan obyek atau lingkungan di sekitarnya, informasi tersebut kemudian diolah sehingga menghasilkan suatu aksi. Proses ini dapat dilakukan secara berulang.

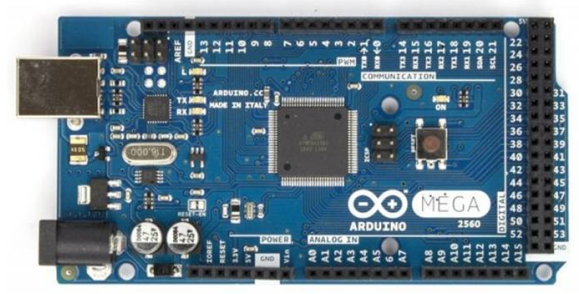

Gambar 1. Board Arduino Mega 2560

Arduino Mega 2560 adalah hardware open source (OSH - Open Source Hardware). Sehingga pengguna diberi kebebasan untuk dapat membuat sendiri rangkaian pengembangannya. Pemrograman board Arduino Mega 2560 dilakukan dengan menggunakan Arduino Software (IDE) yang bisa didapatkan secara gratis karena sifatnya yang open source software.

Chip ATmega2560 telah diisi program awal yang sering disebut bootloader. Bootloader tersebut yang bertugas untuk memudahkan dalam melakukan pemrograman lebih sederhana menggunakan Arduino
Software, tanpa harus menggunakan tambahan hardware lain. Proses memprogram Arduino sangat sederhana, yaitu dengan menghubungkan Arduino melaui kabel USB ke PC atau Mac/Linux, kemudian menjalankan software Arduino Software, dengan cara ini pengguna sudah dapat memulai proses pemrograman chip ATmega2560. Pemrograman Arduino menggunakan bahasa program yaitu bahasa C. Bahasa ini telah dipersingkat dengan menggunakan fungsifungsi yang sederhana sehingga pemula pun bisa mempelajari dengan mudah.

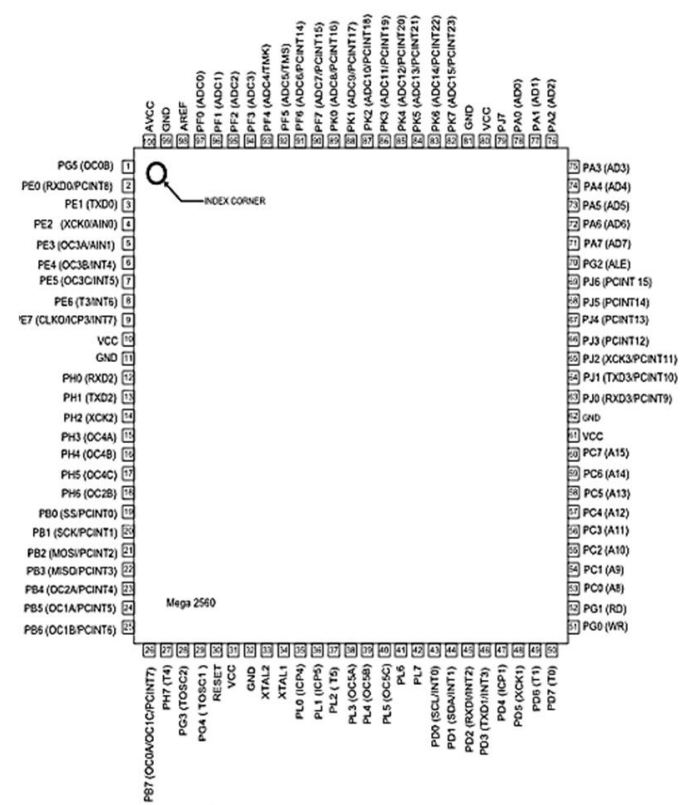

Gambar 2. Pin Konfigurasi Arduino Mega 2560 
Arduino menggunakan software processing yang digunakan untuk menulis program kedalam Arduino. Processing merupakan penggabungan antara bahasa $\mathrm{C}++$ dan java software. Software Arduino dapat diinstal diberbagai operating system (OS) seperti: LINUX, Mac OS, dan Windows.
Software (Integrated Development Environment) IDE Arduino terdiri dari tiga bagian yaitu Editor, Compiler dan Uploader. Dalam penelitian ini, Arduino 2560 digunakan sebagai chip pengendali dalam proses kerja TOP COYS.

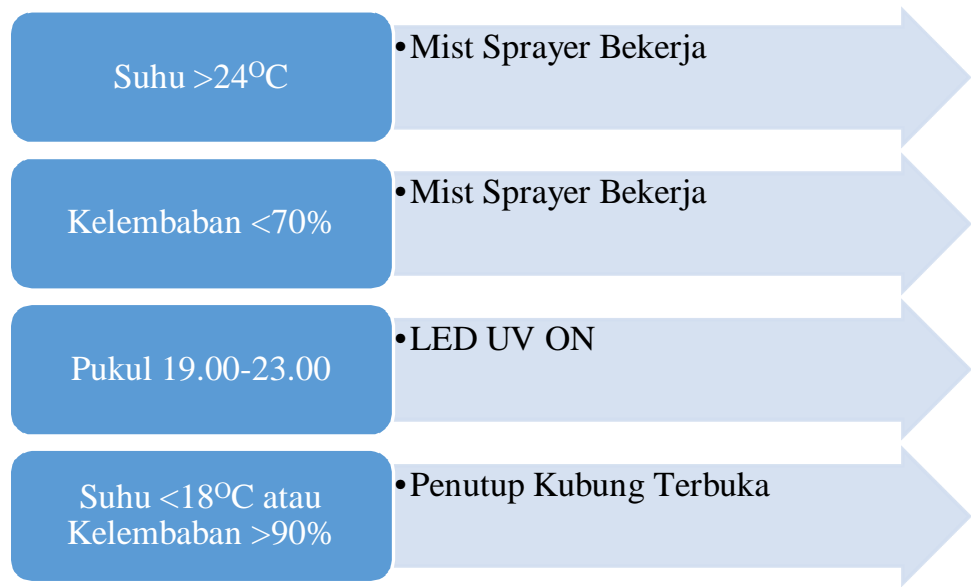

Gambar 1. Cara Kerja TOP COYS

\section{Implementasi dan Evaluasi Alat}

Alat yang telah terpasang kemudian dilakukan monitoring rutin minimal dua minggu sekali untuk memantau perkembangan tanaman dan unjuk kerja dari TOP COYS. Apabila terdapat ketidaksesuaian akan dilakukan evaluasi agar TOP COYS dapat bekerja secara optimal dan maksimal.

\section{HASIL DANPEMBAHASAN}

Pengujian Alat TOP COYS dilakukan pada lahan mitra. Hasil uji yang telah dilakukan memperoleh permasalahan kinerja alat yang tidak sesuai dengan kondisi lingkungan. Hasil uji yang dilakukan tidak ada aliran udara yang masuk ke dalam green house. Sehingga, dilakukan penyesuaian alat kembali untuk memperoleh aliran suhu yang dapat memasuki green house sampai diperoleh aliran udara yang sesuai dengan kondisi lingkungan.

Implementasi alat TOP COYS dilakukan pada lahan kelompok tani ASTHA BUNDA.
Berikut ini merupakan desain alat yang diimplementasikan pada lahan mitra.

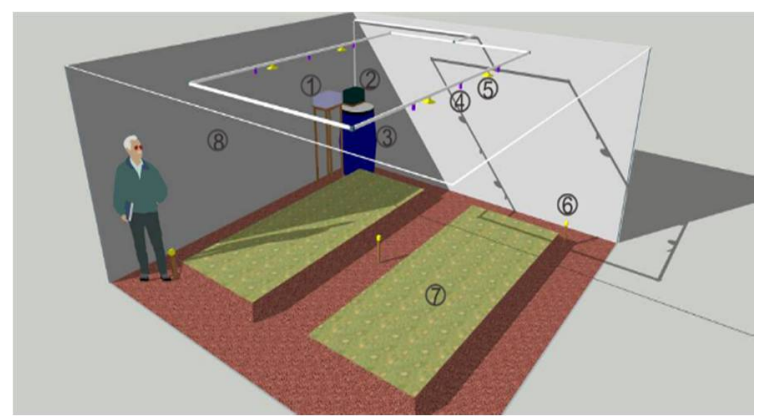

Gambar 2. Pemodelan Sistem TOP COYS Keterangan:

1. Box Kontroller

2. Pompa Air

3. Penampungan Air

4. Mist Sprayer

5. Lampu LED UV

6. Sensor Suhu dan Kelembaban

7. Tempat Penanaman Krisan

8. Penutup Greenhouse

Spesifikasi alat TOP COYS dapat dilihat pada tabel berikut. 
Tabel 1. Spesifikasi Kontroller TOP COYS

\begin{tabular}{|l|l|}
\hline Dimensi & $\begin{array}{l}\text { Panjang : 450 mm } \\
\text { Lebar: } 300 \mathrm{~mm} \\
\text { Tinggi : } 250 \mathrm{~mm}\end{array}$ \\
\hline Jangkauan & $35 \mathrm{~m}^{2}$ \\
\hline Tegangan & $210 \mathrm{~V}-220 \mathrm{~V}$ \\
\hline Arus & $5 \mathrm{~A}$ (maksimal) \\
\hline Display & $-\quad$ Kelembapan \\
& $-\quad$ Suhu \\
& $-\quad$ Jam dan Tanggal \\
& $-\quad$ Lampu ON/OFF \\
\hline
\end{tabular}

Implementasi alat yang telah dilakukan selanjutnya dimonitor terhadap kinerja alat serta dampak yang ditimbulkan akibat penggunaan alat terhadap pertumbuhan tanaman bunga krisan. Monitoring dilakukan secara berkala untuk menyelesaikan permasalahan kinerja alat TOP COYS yang belum dapat bekerja secara optimal serta dampak kinerja alat TOP COYS. Berdasarkan hasil monitoring yang telah dilakukan terhadap alat TOP COYS, diprediksikan produktivitas tanaman krisan mengalami peningkatan sekitar 40-50\%. Prediksi ini ditetapkan berdasarkan pengamatan yang dilakukan terhadap tanaman yang menggunakan alat TOP COYS dibandingkan dengan tanaman yang tidak menggunakan alat TOP COYS serta berdasarkan penuturan dari mitra. Hasil pengamatan terhadap tanaman yang menggunakan alat TOP COYS diperoleh data sebagai berikut:

Tabel 2. Perbedaan Hasil Tanam

\begin{tabular}{lcc}
\hline Perbedaan Hasil Tanam & Tidak Menggunakan & Menggunakan \\
\hline Material & & \\
\hline Biaya Listrik (1 bulan) & Rp. 100.000 & Rp. 50.000 \\
\hline Non Material & & \\
\hline $\begin{array}{l}\text { Ketahanan Hidup Bibit Awal } \\
(2000 \text { Batang) }\end{array}$ & Tanaman Mati: 153 Batang & Tanaman Mati: 24 Batang \\
\hline $\begin{array}{l}\text { Diameter Batang Usia Tanam } \\
1 \text { Bulan (rata-rata) }\end{array}$ & $0,4 \mathrm{~cm}$ & $0,6 \mathrm{~cm}$ \\
\hline $\begin{array}{l}\text { Tinggi Tanaman Usia Tanam } \\
1 \text { Bulan (rata-rata) }\end{array}$ & $15,3 \mathrm{~cm}$ & $20,4 \mathrm{~cm}$ \\
\hline
\end{tabular}

\section{Diagram Perbedaan Hasil Tanam}

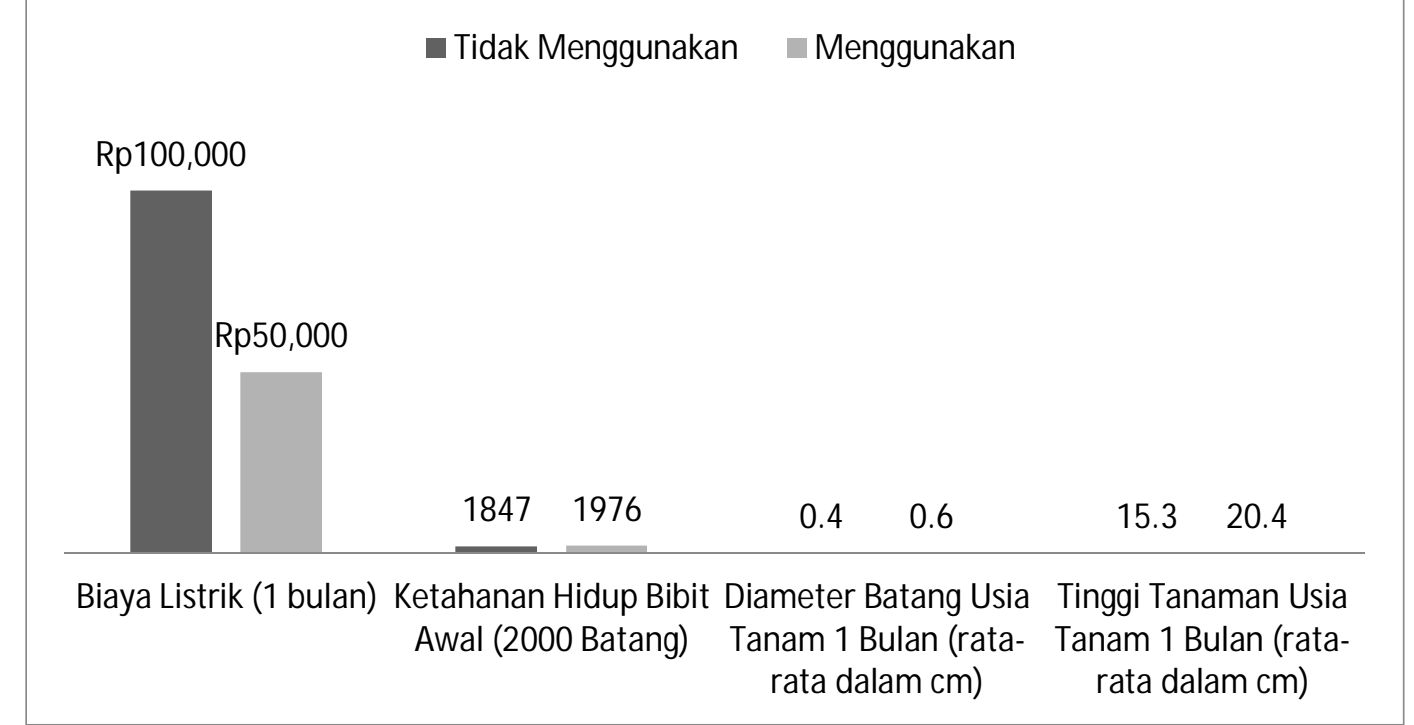

Gambar 3. Grafik Perbedaan

Berdasarkan hasil pengujian diatas, keunggulan alat TOP COYS dibandingkan dengan teknologi alat pengendali lingkungan yang lain yaitu lebih hemat dibandingkan 
dengan tidak menggunakan alat, memiliki ketahanan hidup lebih tinggi, mempunyai diameter dan tinggi yang lebih dibanding yang tidak menggunakan alat.

\section{SIMPULAN}

TOP COYS sangat pontensial untuk meningkatkan produktivitas bunga krisan. TOP COYS lebih hemat dibandingkan dengan teknologi alat pengendali lingkungan yang lain, bunga krisan memiliki ketahanan hidup lebih tinggi dan mempunyai diameter serta tinggi yang lebih dibanding dengan tidak menggunakan TOP COYS.

\section{DAFTAR RUJUKAN}

Anonim. 2011. Bunga November yang Sarat Manfaat.

Diakses dari:http://www.ibujempol.com/bungakrisan/. Pada 25 Oktober 2016.

Anonim. Tanpa tahun. Mengenal Arduino Mega 2560. Diakses dari: http://ecadio.com/belajar-dan-mengenalarduino-mega. Pada 10 April 2017.

Crater, G. D. 1980. Pot Mums, In R. A. Larson (ed.). Introduction to Floriculture. Academic Press, Inc. New York.

Direktorat Budidaya Tanaman Hias. 2007. Standar Operasional Prosedur Budidaya Krisan. Departemen Pertanian, Jakarta.

Kofranek, A. M. 1980. Cut Crysanthemum, In R. A. Larson (ed.). Introduction to Floriculture. Academic Press, Inc. New York

Mum, Fides. 1990. For All Year Round Chrysanthemums. Fides Holland BV, Holland. 